\title{
Fragmentation and hierarchies in Argentina's maternal health services as barriers to access, continuity and comprehensiveness of care
}

\author{
SABRINA SOLEDAD YAÑEZ, Postdoctoral Fellow, Institute for Human, Social and \\ Environmental Sciences, Argentina ${ }^{a}$
}

ssyc19@gmail.com

\begin{abstract}
This paper aims to uncover the ways in which institutional regulations of maternal care services offered by the public health system in Argentina generate various forms of fragmentation and hierarchical organization that create barriers to access, continuity, and comprehensiveness of care. The conceptual and methodological tools of institutional ethnography are used as a guide for analysis of interviews with women and health agents from a province of the country's Western region, as well as participant observation at regional hospitals and local health centers. The barriers identified and analyzed are related to regulations of time(s), space(s), and hierarchies among the health professions involved in service provision related to maternal health.
\end{abstract}

Keywords: maternal health; institutional ethnography; institutional time; institutional space; hierarchies; pregnancy; Argentina; public healthcare.

${ }^{a}$ Sabrina S. Yañez is a postdoctoral fellow at the Institute for Human, Social and Environmental Sciences (INCIHUSA), a regional center of the National Council for Research on Science and Technology (CONICET, Argentina). Her life, work and activism are situated in the province of Mendoza, in the West of the country. She received a bachelor's degree with a Sociology/Anthropology major from Simon Fraser University by means of a Shrum International Scholarship, and a PhD in Anthropology from Universidad de Buenos Aires, Argentina, by means of two consecutive CONICET scholarships.

Sabrina's research focuses on mothering experiences and the regulations of reproductive processes by healthcare services in contemporary Argentina. She has presented her research findings at several scientific meetings, including the Latin American Consultation on Gender, Economic and Ecological Justice, held in Montevideo, Uruguay, in 2013; and the International Sociological Association World Congress held in Buenos Aires in 2012. She has also published various articles in academic journals, including "Paradoxical breasts: the inconstant politics of breastfeeding discourses" (Temas de mujeres, Argentina, 2010), "Revealing Dorothy Smith's contributions to the epistemology and methodology of the social sciences" (DiáLogos, Argentina, 2011) and "From witch hunting in Europe to the eugenic mandate in Argentina: reflections on some of the landmarks of the institutionalization of motherhood" (Nómadas, Spain, 2013), all available online.

She was also selected and awarded a grant to attend DAWN (Development Alternatives with Women for a New Era) Training Institute for young feminists from the Global South, held in Siem Reap, Cambodia, from 10 to 27 October, 2011. 


\section{Introduction}

This article seeks to uncover the ways in which institutional regulations of maternal care services offered by the public health system in Argentina produce various forms of fragmentation and hierarchical organization that create barriers to access, continuity, and comprehensiveness of care. The analysis and discussion of these issues is based on my doctoral field research conducted from 2009 to 2015, which focused on how public health institutions regulate pregnancy, birth, and postpartum experiences of women in Mendoza, a province of Western Argentina. My quest and writing follow the genealogy inaugurated by feminist writer Adrienne Rich (1986), who proposed an analysis of motherhood that distinguishes between experience - the relationship of each woman to her reproductive potential and/or her children - and institution - the appropriation of that potential by powers such as heteropatriarchy, capitalism, Western medicine, and the state. Public health institutions are a privileged site for the crystallization of the institution of motherhood, as they effect both the medicalization of reproductive processes and the control and supervision of demographic processes by the state (Federici, 2010; Nari, 2010). During the fieldwork and the writing process for my doctoral dissertation, I came across several regulations that result in the fragmentation of maternal health services. Once fragmentation has occurred, a process of hierarchical organization follows: only some areas of the population, body, health system, and reproductive processes are considered worthy of care and/or resources.

Fragmentation and hierarchy-building processes occur as a result of the operations of extralocal interests in the routine organization of health care services, particularly the organization of space(s), time(s), and relations among agents. After offering a brief overview of the way public healthcare has been established in Argentina, this article will illuminate how fragmentation and hierarchy are created by the geographical and institutional organization of services, the allocation 
of time within hospitals and healthcare centers, and the unequal distribution of power among healthcare professionals. Fragmentation and hierarchies result in borders and barriers that pose a serious challenge to women's full access to services, as well as to continuity and comprehensiveness of care during pregnancy, birth, and the postpartum period.

\section{Background}

The health system in Argentina has been characterized by the "presence of constant tensions between universalism and particularism, between state intervention and corporate regulation, between unification and fragmentation of jurisdictions and coverage" (Belmartino, 2009: 4). The health system is composed of three subsystems — public, social security, and private - which have not been truly coordinated, causing serious problems for the integration of health policies (PNUD, 2011: 8). My research focuses on the Argentinian public health subsystem, which is well known in the region for providing services that are both wide-ranging and free. It experienced a golden era during the 1940s and 1950s, under the command of President Perón's Health Minister Ramón Carrillo, when the state became the "responsible and guarantor" of the right to health. It propelled a multiplication of universal and free public health services, along with the growth of social security services linked to waged labour (Tobar, 2001: 7). After 1955, the dictatorial regimes that alternately ruled the country dismantled part of Carrillo's system by driving decentralization processes that transferred responsibilities for health services from national to provincial and municipal authorities. In Argentina, decentralization processes should not be considered a federal triumph that endowed provinces with greater autonomy. Rather, they have responded to unilateral decisions made by central authorities, aimed at liberating economic resources and facilitating the introduction of a market rationality for service management (Rovere, 2011: 23). Moreover, decentralization was not driven by a will to 
incorporate citizens into decision-making processes through territorialization strategies, nor was it preceded by a transfer of management capacities or resources to the provincial and municipal governments. Hence, decentralization accentuated existing regional disparities in needs, resources and policies (Cetrángolo et al, 2007; Rovere, 2004).

The territorial fragmentation caused by decentralization was accompanied by institutional fragmentation with the advent of neoliberal policies in the 1980s and 1990s. Under these democratic governments, financial administration was detached from service provision, putting decision making for key issues in the hands of those most disconnected from local needs. In addition to decentralization, the neoliberal turn fostered processes of privatization, deregulation, and focalization under the terms imposed by international financing organizations. The combination of these processes resulted in an irregular health system, with unequal access according to the capacity to pay for services, the possibility of accessing social security through waged labour, socioeconomic status, and rural and urban locations, as well as other factors. The situation became worse when the already weakened "universal" system had to withstand the effects of the 2001 economic crisis that forced unemployment and poverty rates to skyrocket. As a result, many were left without social insurance and had to seek out publicly-funded health services. The health system was declared in a state of emergency by the provisional authorities in 2002 and remained so throughout the Kirchner administration (presided first by Néstor Kirchner and then by his wife and former senator Cristina Fernandez) from 2003 to 2015.

The period ranging from the 2001 crisis to the end of the Kirchner era in 2015 comprises the time frame of my study. In general terms, this period was characterized by a reorganization of public health services based on a double logic. On the one hand, there existed a rights discourse that opposed the neoliberal rationality of self-responsibility and self-management, which was attempting to revive the role of overseer of the National Health Ministry that aimed at policy 
integration. On the other hand, fragmentation and focalization continued, which is evident by the essential programs that were partially funded through loans from the World Bank and other international financial institutions, such as the major maternal and child health policies of the period. These programs were organized around the improvement of demographic indicators, such as maternal and child deaths. The persistence of such extralocal influences in health policy is to a great extent responsible for the fragmented and hierarchical organization of the services analyzed in this article.

\section{Notes on methodological issues}

My research process was informed by the conceptual and methodological tools of institutional ethnography as proposed by sociologist Dorothy Smith (2005, 2006). Institutional ethnography has a double aim: 1) to produce "maps" of the ruling relations and the institutional complexes aimed at allowing people to discern their own social locations and move more knowingly; and 2) to continue building knowledge and methods for ethnographically exploring those processes and relations that generalize beyond the particular instance, which are central for ruling in contemporary Western and Westernized societies (Smith, 2005:51). Smith describes the institutional ethnographic project as a four-part package that considers that "individuals are there;

they are in their bodies; they are active; and what they are doing is coordinated with the doings of others" (Smith, 2005:59). In this project, language is conceived as central, as it links the local to the institutional or extralocal by coordinating people's consciousnesses and subjectivities (Smith, 2005:94). The notion of extralocal is used to refer to the way ruling relations organize everyday/everynight settings based on priorities and rationalities that are external to that setting and the relationships contained within it. According to Smith, "the disclosure of the extralocal 
determinations of our experience does not lie within the scope of everyday practices", but requires tracking them through specialized investigation (Smith, 1987:3).

Finding and analyzing texts — understood as "material artefacts that carry standardizing messages" including print, film, photographs, television, mass and electronic media, and radio enables the researcher to examine the coordination and regulation of people's work in relation to institutions (Bisaillon, 2012: 620). Here, work and institution are also defined quite differently from other perspectives. Smith's generous concept of work $(2005: 46,154)$ builds on lessons from feminist conceptions and directs attention to intentional activities that take time and effort, are done in an actual place, with definite resources and in coordination with the work of others. Institutions are defined as "complexes embedded in the ruling relations that are organized around a distinctive function such as education, health care and so on" (Smith, 2005: 225). Institutions have the capacity to generalize: people working at institutional settings are actively transforming experiences and particular needs into standardized and generalized versions, mostly through the use of textual devices (laws, protocols, forms, statistics, etc.).

Several studies have used institutional ethnography as a means to trace the organization of health services (Mykhalovskiy \& McCoy, 2002; Rankin, 2003; Rankin \& Campbell, 2009; Sinding, 2010), including the organization of obstetric care provision (MacKinnon, 2006). In these studies, attention to work enables the production of "detailed descriptions of the everyday, often mundane tasks involved in getting and providing care and treatment", revealing "how access is more readily gained, and needs are more routinely addressed, for some patients than for others-knowledge that can allow us to trace the production of health care disparities" (Sinding, 2010: 1657).

Fieldwork was conducted in Mendoza province from 2008 to 2015. The first stage sought to record the experiences of women whose pregnancies, births, and postpartum periods had put 
them in contact with the public health system. Eight women who reside in both urban and semirural areas of greater Mendoza were interviewed in-depth. Interviews were transcribed and coded in search of work activities as defined by institutional ethnography. "Health work" tasks emerged as central in women's accounts (Mykhalovskiy\& McCoy, 2002; Sinding, 2010), revealing the myriad activities women carry out in order to care for their pregnancies, to go through institutionalized birth routines, and to move through the postpartum period while facing a lack of services. This "health work" was performed in coordination with that of health workers at public hospitals and primary care centers. Hence, the second stage of fieldwork focused on the provisions for care - or their absence - at public health institutions. This stage included 15 interviews with health workers, including certified midwives, social workers, and doctors (pediatricians, obstetricians, and family specialists), some of whom have occupied hierarchical positions at the provincial health ministry and special programs. Participant observation was also carried out both at the province's major maternity ward and at urban and rural municipal health centers where pregnancy and postpartum appointments take place. Special attention to the use of institutional texts such as forms, medical records, audit material, surveys, and measuring tools was crucial in this research. These texts further revealed the organization of time, space, and resources within institutions and the way care work is supervised by higher levels of institutional authority.

\section{Institutional spaces: fragmenting access through risk perception}

Health researcher Cecilia Canevari has written that within the organization of space lies the rationality of the system (Canevari, 2011: 95-96). Maternal health services in Mendoza are organized on the basis of two national strategies allegedly aimed at reducing maternal and neonatal deaths: a strategy of regionalization of perinatal services and a perinatal risk approach. 
Regionalization implies the regional rearrangement or "rationalization" of services so that human and material resources that are deemed to be dispersed can be concentrated and maximized according to the level of complexity of the care offered. It also requires a high degree of coordination among the institutions involved (Schwarcz, 2010:11). The risk approach, applied to perinatal services, requires that pregnancies and newborns be classified, according to their social and medical conditions, into low risk or high risk $^{1}$ and hence channeled into different types of services. While low risk pregnancies are monitored at municipal health centers, women with pregnancies deemed high risk are required to attend check-ups at hospitals. Regardless of risk, all women are expected to give birth at hospitals. Despite their framing as services for women and children, a thorough analysis of the way these strategies are implemented, geographically and institutionally, reveals that they stem from priorities that are extra-local to women's needs and experiences.

\section{The regionalization strategy and the persistence of territorial inequalities}

The regionalization strategy is supposedly aimed at integration of the health system. However, the relations among institutions of different complexity levels and resources are affected by hierarchies that pose obstacles for service provision and coordination. Local healthcare centers have much smaller budgets than hospitals so they may channel women to higher complexity providers for lab tests or ultrasounds. These higher complexity institutions sometimes deny women access to services by arguing that they are only available for high-risk cases. Conversely, when hospitals channel women to health centers for post-partum follow-up through a computerized system, these appointments are not always respected by health center

\footnotetext{
${ }^{1}$ Notice that in this classification there are no pregnancies without some level of risk. The pathologization of reproductive activities has been essential in order for the state and the medical corporation to exert control over these activities. For additional details about the process of institutionalization, refer to Yañez (2013).
} 
front desk staff because they argue that this affects their time and resource organization. In this scenario, women are often caught up in power relations between institutional spaces that become barriers to full access to healthcare during pregnancy and after birth.

As for the perinatal risk approach and its classifications, anthropologist Ellen Lazarus demonstrates that by channeling "demand" on the basis of perceived risk, it produces differentiated access to care, reinforcing rather than bridging inequalities and risk of complications (Lazarus, 1994). The same can be said of the Argentinian strategy. Women whose pregnancies are classified as low risk are usually followed-up at health centers located in their neighborhoods, by certified midwives or obstetricians, with a greater chance of receiving a more personalized type of care, with more time for getting their concerns and needs covered. Conversely, women whose pregnancies are deemed high risk have to go to regional hospitals where they may be seen by different professionals throughout their pregnancy, and exposed to an array of health specialties (front desk staff, nurses, dietitians, social workers, cardiologists, laboratory personnel, pharmacists, etc.). These women report receiving contradictory indications from the many professionals involved in their care, and long for the guidance of a health agent they can trust to provide coherent information (Lazarus, 1994:32).

The regionalization strategy may state as its aim the provision of services according to women's needs, but when coordination is not guaranteed it actually reinforces inequalities in access based on place of residence. During my fieldwork, it became evident that some rural areas of the province are not enjoying the full range of perinatal services due to the absence of high complexity services in the area and the lack of proper transportation and communication arrangements that would allow for women to be transferred to institutions that are better prepared to deal with emergency obstetric and neonatal care. A low complexity hospital located in one of these areas, 40 minutes away from the closest high complexity provider, has been repeatedly 
showcased in the media as a result of maternal and neonatal deaths associated with failures in the transfer system (ElSol Online, 2010, Diario Vox, 2010, Diario Noticias Mendoza, 2013). The situations portrayed in the media include ambulances that do not reach remote areas on time due to the poor state of roads and the long distances to be traveled and that break down on the road to the hospital without a replacement vehicle to complete the trip. There have also been reports of single ambulances used to deal with several emergencies and emergencies that were handled without a doctor present during the trip. A certified midwife that works at this hospital commented in an interview that she transfers women to a higher complexity hospital if there is a minimal sign of risk because she is aware of the impossibility of responding to emergencies adequately as they do not have operating rooms or transfusion services. However, her decisions to transfer women are constantly called into question by the staff at the larger hospital.

The constant complaints of the population served by this low complexity hospital and those in other rural communities led the provincial health ministry to redefine the concept of "high risk pregnancy" so that it includes those women who live in "extreme rurality," i.e. inhabitants of remote and inaccessible areas of the province (Perez, 2013). These women are required to leave their homes, their families, and responsibilities some time before their due dates and live at a residence set up by the government near the hospital, awaiting the onset of labour. Hence, instead of reaching out to these women with proper services, investing in well-equipped transportation and making trained personnel and resources available at the community level, it is women who are made responsible for their own care, having to put on hold their daily lives in order to breach the access gap. In the end, the regionalization strategy only contributes to reinforce territorial inequalities in access, just as decentralization policies did in the past. 


\section{Spatial organization at maternity wards: mobilizing institutional priorities}

When observing the spatial organization at healthcare institutions, it becomes evident that each stage of the reproductive process occurs in distinct spaces, where resources are assigned according to institutional priorities. The province's major maternity ward, located at a large urban hospital, offers clear examples of how priorities shape space organization and the disconnections they generate. According to the doctors interviewed, the maternity ward is divided into rigid compartments, including high risk and low risk sectors, delivery area, pregnancy follow-up rooms, residence for mothers, a human milk bank, and others. Each sector has its own authority and there is no fluid communication among them. Hence, we see how the spatial organization of the maternity ward produces a fragmentation of the reproductive process and a categorization according to the level of risk appraised.

The disconnection of spaces is accompanied by hierarchical organization, where some aspects of the reproductive process are assigned priority status and hence receive more resources and attention. The Human Milk Bank, for instance, has passed international standards evaluations (ISO 9001/2008) and functions with advanced technology acquired with funds from the National Maternal and Child Health Program, while the delivery area is subject to constant complaints due to the lack of basic infrastructure to guarantee sufficiency of space, comfort, and privacy. After giving birth, women may stay for hours in a corridor, cold and uncomfortable in a stretcher, waiting for a bed to be available in the postpartum rooms. Once there, they share a room with as many as five other women and their babies, sometimes without a proper lavatory. Women interviewed reported that there was no hot water to take a shower, there were cockroaches in some of the rooms, and the food they received was of a worse quality than what they were offered when admitted during pregnancy. 
One of the obstetricians interviewed commented that they do not even have a computer at the postpartum sector and that there are no specific services for high risk postpartum, as compared to specialized care provisions for high risk pregnancy and newborns. Another obstetrician claimed that the infrastructure problem had less to do with a lack of financial resources than with a lack of willingness by administrators to make the necessary investments (small, compared with the ones made in neonatal technology, for instance) to offer better services for women during their labour and postpartum stay.

These discrepancies in the spaces and resources dedicated to certain parts of the reproductive process respond to the fragmentation that occurred as a result of the institutionalization and medicalization of reproduction, parallel to the development of industrial capitalism. What Robbie Davis-Floyd (2001: S6) has termed the technocratic paradigm of childbirth "continually separates the individual into component parts, the process of reproduction into constituent elements, and the experience of childbirth from the flow of life" while effecting an underlying separation of mind and body. The processes of fragmentation and separation result in the possibility of paying differential attention to the "product" of gestation (fetus) and of birth (infant) while considering the new mother a "sub-product" (Davis-Floyd, 1987: 294) who is not worthy of much care.

Within health care institutions other kinds of borders prevail as well: those between freecirculation and restricted areas, which express power relations between authorized and authoritative personnel, "patients" and their families. Restricted areas are guarded by security personnel who control who can enter and leave; these guards are usually responsible for effecting the separation between women and their partners or other family members. Once admitted into the hospital, women tend to feel they are not free to leave (Canevari, 2011: 96), as their bodies are now subjected to the decisions made by institutional agents and their texts. 


\section{Institutional time: fragmenting bodies and experiences}

In public healthcare institutions, time allocation and time perception are ruled by texts created to administer the use of limited material and human resources: job contracts, budget sheets, forms, protocols, appointment systems, graphs charting uterine growth or cervix dilation progression, and many others. Institutional time is chronological, linear, standardized, and managed under the rationality of efficiency. This conception of time has an impact on service quality, as it denies each woman the possibility of making autonomous decisions based on her own embodied perception of the times of gestation, birth, and postpartum. The organization of time within healthcare institutions helps impose discipline on patients (pregnant and birthing women, in this case): those who hold power positions are able to make others wait, while those in subordinate positions must be willing and ready to wait (Canevari, 2011: 96). Time allocation and distribution reflect institutional priorities rather than women's needs. At the hospital where observations were conducted, doctors in charge of high risk pregnancy check-ups reported they had to see five patients per hour. This means they can only dedicate 12 minutes per visit to women who need special attention and care with complex situations including chronic illness or complications generated by pregnancy such as gestational diabetes or preeclampsia.

The control of time during labour and delivery is an extreme example of the imposition of extralocal priorities on very singular processes that depend on the embodied experience of time each woman has. For instance, some of the obstetricians interviewed spoke, in accordance with obstetrical texts, about "correcting" slow labour progress and dealing with "stagnant dilation." The partograph used to draw the curve of labour progress in a standardized sheet with alert lines inserts extralocal ways of measuring time and risk into the routine work of doctors and midwives in hospitals. Moreover, at overcrowded hospitals, women report having been administered 
synthetic oxytocin in order to speed up labour and "free up space" for other women waiting to deliver.

Another example of how institutional time is organized by extralocal interests, rather than women's experiences and needs, comes up in the allocation of time for the rotation of gynoobstetric residents through the different maternal and reproductive health services. According to the residents interviewed, in their four years of training they spend only two weeks at the postpartum sector. The underestimation of postpartum as an important part of the reproductive continuum, which needs care and specialized services when complications arise is also evident in the curricula of medical science. A participant noted that medical students were told by the instructor that they would "skip" postpartum as a class topic and just complete an assignment, so they could "move on to more interesting things." The way services are scheduled at local healthcare centers is another example of barriers to access created by institutional time. A social worker of the provincial reproductive health program remarked that women are often blamed for not having enough check-ups during pregnancy, but little is done to assess the barriers which prevent women from attending these appointments. For instance, women are required to line up at $4 \mathrm{am}$ at the center's entrance in order to secure their place. Sometimes they have to cross dangerous areas (where women have been raped or robbed) in the dark, at hours where no public transportation is available. The social worker claimed that the authorities at these institutions are probably aware of these circumstances, but refuse to make changes to the appointment system because they believe that women should be willing to adapt to service provisions given that they are offered free of charge. 


\section{Institutional hierarchies: inhibiting comprehensiveness}

The production and maintenance of hierarchies among health agents is another important factor to be considered when analyzing the creation of barriers to access and quality. Those who occupy higher positions in the healthcare system, such as doctors and administrators are often in a position of privilege which makes them more attuned to institutional discourses and extralocal interests, while those in more subordinate positions, such as midwives and social workers, can attain a critical distance that makes them aware of the effects of extralocal regulations on women's reproductive experiences and on their own experiences as workers.

At the hospital, care work is organized hierarchically, with well-defined functions for each stratum. This division of labour is maintained even when it may result in harm to the women using the services. Midwifery students interviewed commented they were appalled at this strict division during their first encounter as interns with institutionalized birth at the major maternity unit in the province. They noticed a doctor would not fulfill a task assigned to stretcher-bearers or nurses, even when necessary due to the absence of the latter. Doctors or older midwives laughed at these students when they went to get a blanket for a woman who was cold, as that is supposed to be the nurses' job. They reported feeling a need to "ask for permission" from some authorized staff member to care for women, comfort them, help them clean themselves after delivery, lest their actions be judged as intruding into other agents' spheres. Argentinian midwife and writer Raquel Schallman, who has extensive experience working at maternity units, has asserted that there is a "chain of subordination" at healthcare institutions where administrators subdue doctors, doctors subdue midwives, and midwives subdue women (Schallman, 2007: 182).

Hierarchies in healthcare work do not originate in the hospital but stem from the way medical disciplines construct the limits and scope of their field. For instance, obstetrician- 
gynecologists are apprehensive about the possibility of other specialists overlapping with their field. According to a family doctor interviewed, the Obstetrician-gynecologists Federation of Argentina denied family doctors the ability to prescribe contraceptives, insert intrauterine devices, or take samples for pap tests. This was a detriment to women's access to reproductive services, as some community healthcare centers have family doctors but no obstetriciangynecologists. Another example of this protectiveness of disciplinary boundaries emerged during fieldwork in a community healthcare center where certified midwives offer sexual and reproductive care services. When they need to send women to higher complexity centers for lab tests or to get medication, women can be turned away because their referral came from a midwife, rather than an obstetrician or gynecologist.

Obstetrician-gynecologists interviewed revealed tensions they experience with other professions, especially those dealing with legal matters. Malpractice complaints and trials are perceived as latent threats affecting their professional autonomy and practice, motivated by the intrusion of lawyers into the field of health. Obstetrician-gynecologists may justify interventionist practices with concerns about being tried for not doing enough. Lawmakers are also criticized for passing laws that do not fully recognize the difficulties faced by those "working in the trenches" in maternity wards. Argentina passed a law in 2004 stating the rights of women and their families during birth, including the right to be informed about and to provide/deny consent for practices performed and the woman's right to have a companion of her choice throughout the hospital stay. In 2009, a law passed to prevent and eradicate violence against women included a specific reference to obstetric violence. One of the obstetrician-gynecologists interviewed demanded that legislators pass a law to defend their practice and prevent unnecessary malpractice trials. So instead of focusing on the need to transform regulations to provide women-centered services, 
some healthcare professionals view these laws as an imposition and intrusion from legal professions into their field of practice.

The hierarchical division of labour in maternal health services that was most evident during fieldwork was that between obstetrician-gynecologists and certified midwives. According to the midwives interviewed, they are taught subordination during their university training, controlled by medical knowledge. ${ }^{2}$ They report being discredited by professors, primarily male doctors, who suggest that they will never occupy important positions within hospitals. The control exerted by doctors was evident in the decision to teach them "just the necessary" to fulfill their role and not more so as to prevent them from making autonomous decisions and to make them dependent on doctors' knowledge and authority.

The autonomy of midwives is also impacted by legal definitions of their field of action. Midwives have been fighting for a provincial law regulating their professional activities and allowing them a wider margin of action. However, recently the House of Senators denied them this opportunity suggesting that it would lead to higher abortion rates because the midwives intended to provide counseling on reproductive health and contraceptive use. The limitation of midwives' practice during the medicalization of reproductive activities, which in Argentina took place during the first half of the twentieth century, meant that women lost the presence of traditional midwives who were experienced caregivers and could provide more comprehensive and personalized services.

Within hospitals, certified midwives have a fundamental role in the daily functioning of maternity wards, but this role is viewed as being subordinate to that of doctors. During

\footnotetext{
${ }^{2}$ Since the second half of the twentieth century, midwife training in Argentina has been organized under the control of medical schools. They receive an undergraduate degree after completing a four year training program. The career is usually part of the programs offered by medical schools at universities. In Mendoza, the only medical school currently offering the degree of certified midwife is at a private university.
} 
interviews, doctors described midwives as "technical staff with a well-defined field of action" and as "a good resource, undervalued by medical hegemony but valued by mothers because of their support, a resource that does not invade what is not their domain". On the other hand, the accounts of midwives themselves reveal more conflict than doctors' remarks - they talk of being thrown out of a delivery room to make space for the training of medical students and residents; and they describe situations in which their observations about labouring women are not heard by doctors. One midwife even spoke of witnessing the death of a woman as a result of the underestimation of signs she had perceived but doctors disparaged.

A new generation of young university-trained midwives is trying to recover a genealogy that connects them to traditional midwives. Their awareness of subordination makes them critical of institutionalized knowledge and practices and the power relations they generate. Their vision of reproductive processes is not focused on pathological events but on a more comprehensive understanding of these processes as socially situated experiences. They are critical of the fragmentation of bodies and the disconnection of reproduction from sexuality and from the flow of life, and they are aware of the effects of institutional violence on women's mothering experiences.

Some of these midwives have been able to access jobs at primary care centers through their participation in the National Program of Community Medicine ${ }^{3}$. This participation has allowed them to provide services related to reproduction and sexuality along a continuumcounseling on and prescribing of contraceptive methods, carrying out low risk pregnancy and postpartum checkups, organizing birth preparation courses, and working alongside psychologists

\footnotetext{
${ }^{3}$ A program launched in 2004 to strengthen the Primary Health Care strategy in local healthcare systems through interdisciplinary work of the health and social sciences and the incorporation of indigenous health agents (http://www.msal.gov.ar/medicoscomunitarios/index.php/institucional/objetivos). Unfortunately, the scope of the program has been quite limited and its funding, again, comes from international loans.
} 
and social therapists to offer comprehensive care. However, these are isolated advances, not longterm policy changes, and the impact of this modality of care on women's health and satisfaction has not been evaluated because it is not prone to the kind of quantitative analysis prevalent in current public health policy. It tends to be more concerned with mortality/morbidity indicators and with the administration of limited resources.

\section{Closing remarks}

Throughout my doctoral fieldwork and analysis, I discovered constant tension between women's reproductive experiences lived as a continuum in which material, emotional, and relational conditions are interweaved with sexuality and reproductive processes, and the fragmentation effected by institutionalization and medicalization. Fragmentation takes many forms: territorial, spatial, temporal, across health disciplines and professions, according to risk allocation, separation of body from context and bodily fragmentation, and breakup of the reproductive process. Once fragmentation has occurred, the resulting parts are assigned different priority levels and hierarchical statuses on the basis of which resources are allocated. For women, these rifts and hierarchies signify a weakened access to comprehensive services that can take into account the singularity of their needs and living conditions. While traditional midwifehealers knew, and sometimes shared, these conditions and hence could provide more continuous and appropriate care for women during reproductive and non-reproductive events, institutional services, even when provided by caring agents are organized by extralocal priorities that require homogenization, standardization and reification.

Some of the most egregious consequences of the fragmentation and hierarchical processes found within maternal health care are the inadequacy or inexistence of services focusing on the postpartum period ( for both "normal" or "complicated" cases), maternal mental health and 
sexual health. These absences mean that women have to carry out a heavy load of health work to fill the gaps and failures of the system. Women interviewed described postpartum complications that the system was not prepared to resolve with specific services, so they had to resort to emergency services, for instance. Sometimes they were late receiving care, due to the difficulties of dealing with a newborn and the lack of postpartum control provisions; by the time they got to a service, the complications were exacerbated and some of them even required hospitalization.

Although mental health and sexual health are considered to be part of a comprehensive understanding of health, as defined by the World Health Organization ${ }^{4}$ and by the national healthcare strategy ${ }^{5}$, the risk approach does not take them into account. The difficulty of measuring these components of health and their impact on socio-demographic indicators namely maternal and neonatal mortality and morbidity - through standardized instruments leaves them out of policy priority and resource allocation. Just as with postpartum complications, it is women themselves who are responsible for managing these aspects of their health needs.

This article has analyzed the organization of time, space and professional relations within healthcare institutions providing maternal health services in Argentina. The analysis has revealed that institutional organization responds to extralocal priorities rather than to local women's needs. These extralocal priorities are linked to demographic policies that tie national governments to the achievement of goals established by international organizations that provide funding for social

\footnotetext{
${ }^{4}$ Preamble to the Constitution of the World Health Organization as adopted by the International Health Conference, New York, 19-22 June, 1946; signed on 22 July 1946 by the representatives of 61 States (Official Records of the World Health Organization, no. 2, p. 100) and entered into force on 7 April 1948.

${ }^{5}$ According to the National Health Ministry, "health, understood as a state of complete physical, mental and social wellbeing, and not just the absence of infections or light, strong or serious illnesses, in harmony with the environment, is a constitutional right that each of can and must exercise" (http://www.msal.gob.ar/index.php/home/mision-visiony-objetivos/55-temas-de-salud-de-la-a-a-la-z).
} 
programs, including healthcare programs. Under current ruling relations, public policies linked to the neoliberal model respond to a rationality of resource saving and efficiency. In this scenario, rather than a right, health has become an expense that has to be carefully managed. Furthermore, the recent transformation in scientific conceptions of human bodies, through the development and use of high technology and the emergence of evidence-based medicine, has also been characterized by a primacy of abstraction, standardization and commercialization, drifting farther away from the singularity and diversity of women's experiences and needs. In the case of obstetrics-gynecology, this has fostered the drive to fragmentation, over-medicalization, and hyper-specialization. These matters are not just symbolic or discursive, but underlie the daily organization of time, space and professional hierarchies within healthcare institutions, creating significant barriers for women's access to continuous and comprehensive care during pregnancy, birth and the postpartum period.

Acknowledgements: I would like to thank my supervisor and mentors who generously shared their time and expertise for the completion of the dissertation. Two successive scholarships granted by the National Research Council made research and writing possible.

\section{References}

Belmartino, S. (2009). Las políticas de salud en el siglo XX: legados históricos. 5th Forum del Bicentenario. Retrieved from www.unsam.edu.ar/escuelas/politica/centro_historia_politica/ material/190.pdf

Bisaillon, L. (2012). An Analytic Glossary to Social Inquiry Using Institutional and Political Activist Ethnography. International Journal of Qualitative Methods, 11(5).

Canevari, C. (2011). Cuerpos enajenados. Experiencias de mujeres en una maternidad pública. Santiago del Estero, Barco Edita, Universidad Nacional de Santiago del Estero. 
Cetrángolo et al. (2007). Recursos humanos en los hospitales públicos y centros de atención primaria de la provincia de Mendoza. Diagnóstico y recomendaciones de política. Buenos Aires, CEPAL.

Congress of Argentina (2004). Law 25.929. Rights of parents and newborns during birth.

Retrieved from http://servicios.infoleg.gob.ar/infolegInternet/anexos/95000-99999/98805/ norma.htm

Congress of Argentina (2009). Law 26485 Of comprehensive protection of women to prevent, penalize and eradicate violence against women in the areas where they develop their interpersonal relations. Retrieved from http://servicios.infoleg.gob.ar/infolegInternet/anexos/ 150000-154999/152155/norma.htm

Davis-Floyd, R. (1987). Obstetric Training as a Rite of Passage. Medical Anthropology Quarterly, 1(3): 288-318.

Davis-Floyd, R. (2001). The technocratic, humanistic, and holistic paradigms of Childbirth. International Journal of Gynecology \& Obstetrics, 75, S5-S23.

Diario Noticias Mendoza (2013). Un bebé murió en Lavalle por fallas en la atención obstétrica. Print edition. 16/04/2013.

Diario Vox (2010). “Crisis en salud: otra muerte dudosa y nuevos paros”. Retrieved from http://www.diariovox.com.ar/novedades/index/crisis-en-salud-otra-muerte-dudosa-y-nuevosparos $[18 / 10 / 2010]$

Elsol Online (2010). Acusaron al médico de guardia por la muerte del bebé en Lavalle. Retrieved from http://www.elsol.com.ar/nota/38262/provincia/acu saron-al-medico-de-guardia-por-lamuerte-del-bebe-en-lavalle.html [16/09/2010].

Federici, S. (2010). Calibán y la bruja. Mujeres, cuerpo y acumulación originaria. Madrid, Traficantes de Sueños. 
Lazarus, E. (1994). What do women want? Issues of choice, control and class in pregnancy and childbirth. Medical Anthropology Quarterly, 8 (1), 25-46.

MacKinnon K. (2006). Living With the "Threat" of Preterm Labor: Women's Work of "Keeping the Baby In”. Journal of Obstetric, Gynecologic, \& Neonatal Nursing, Vol. 97.

Mykhalovskiy, E. \& McCoy L. (2002). Troubling ruling discourses of health: using institutional ethnography in community-based research. Critical Public Health, Vol. 12, No. 1, 17-37.

Nari, M. (2004). Políticas de maternidad y maternalismo político. Buenos Aires 1890-1940. Buenos Aires, Editorial Biblos.

Perez, C. (2013). Luego de la polémica, apuran las mejoras en el hospital Sícoli. Diario UNO, Mendoza. Retrieved from http://www.diariouno.com.ar/mendoza/Luego-de-la-polemicaapuran-las-mejoras-en-el-hospital-Sicoli-20130420-0001.html [20/04/2013]

Rankin, J. (2003). Patient satisfaction': knowledge for ruling hospital reform - An institutional ethnography. Nursing Inquiry, 10(1), 57-65.

Rankin, J. \& Campbell M. (2009). Institutional Ethnography (IE), Nursing Work and Hospital Reform: IE's Cautionary Analysis. Forum: Qualitative Social Research, Vol. 10, No. 2, Art. 8, May, 1-21.

Rich, A. (1986). Of Woman Born. Motherhood as Experience and Institutio. New York, WW Norton [1976].

Rovere, M.(2004). La Salud en la Argentina: Alianzas y Conflictos en la Construcción de un Sistema Injusto. La Esquina del Sur, May edition.

Rovere, M. (2011). El área metropolitana evidencia las fallas de nuestro sistema de salud.

Conference at the VIII Foro Metropolitano, Universidad Nacional de La Matanza.

Schallman, R. (2007). Parir en libertad. En busca del poder perdido. Buenos Aires, Grijalbo. Schwarcz, A. (2010). Regionalización de la Atención Perinatal. Ministerio de Salud de la Nación. Centro Latinoamericano de Perinatología (CLAP/SMR)-OPS/OMS. 
Sinding, C. (2010). Using Institutional Ethnography to Understand the Production of Health Care Disparities. Qualitative Health Research, 20(12), 1656-1663.

Smith, D. (1987). The Everyday World As Problematic: A Feminist Sociology. Boston, Northeastern University Press.

Smith, D. (2005). Introduction. In D Smith (ed.) Institutional Ethnography as Practice. Lanham, Rowman and Littlefield Publishers, 1-11.

Smith, D. (2006). Institutional Ethnography. A Sociology for People, Toronto, Altamira Press.

Tobar, F. (2001). Breve historia de la prestación del servicio de salud en la Argentina. Medicina y Sociedad. Retrieved from www.ms.gba.gov.ar/sitios/regionsanitaria6/.../MedicinaSanitaria 12.pdf

UNDP (2011). Aportes para el desarrollo humano en Argentina. El sistema de salud argentino y su trayectoria de largo plazo: logros alcanzados y desafios futuros. Buenos Aires.

Yañez, S. (2013). De la caza de brujas en Europa a los mandatos eugenésicos en Argentina: reflexiones sobre algunos hitos del proceso de institucionalización de la maternidad. Nómadas. Revista Crítica de Ciencias Sociales y Jurídicas, Universidad Complutense de Madrid, No 37, 1-17.Retrieved from https://pendientedemigracion.ucm.es/info/nomadas 137/sabrinayanez.pdf 